\title{
A diagnosis based on the electrocardiogram before laboratory results were available
}

\author{
S.L. Gerritse · E.H.C.C. Janssen
}

Published online: 13 May 2015

(C) The Author(s) 2015. This article is published with open access at Springerlink.com

A 81-year-old male patient is brought in by ambulance with persistent diarrhoea and subacute symptoms of lethargy, weakness of the leg muscles and malaise. He is taking perindopril $4 \mathrm{mg}$ twice a day. On physical examination you find a decreased level of consciousness and a (pre-existing) systolic murmur, fitting his mitral valve insufficiency. His electrocardiogram on admission is enclosed in Fig. 1. What would you expect to find in your laboratory results?

You will find the answer elsewhere in this issue.

Open Access This article is distributed under the terms of the Creative Commons Attribution License which permits any use, distribution, and reproduction in any medium, provided the original
Fig. 1 Electrocardiogram on admission

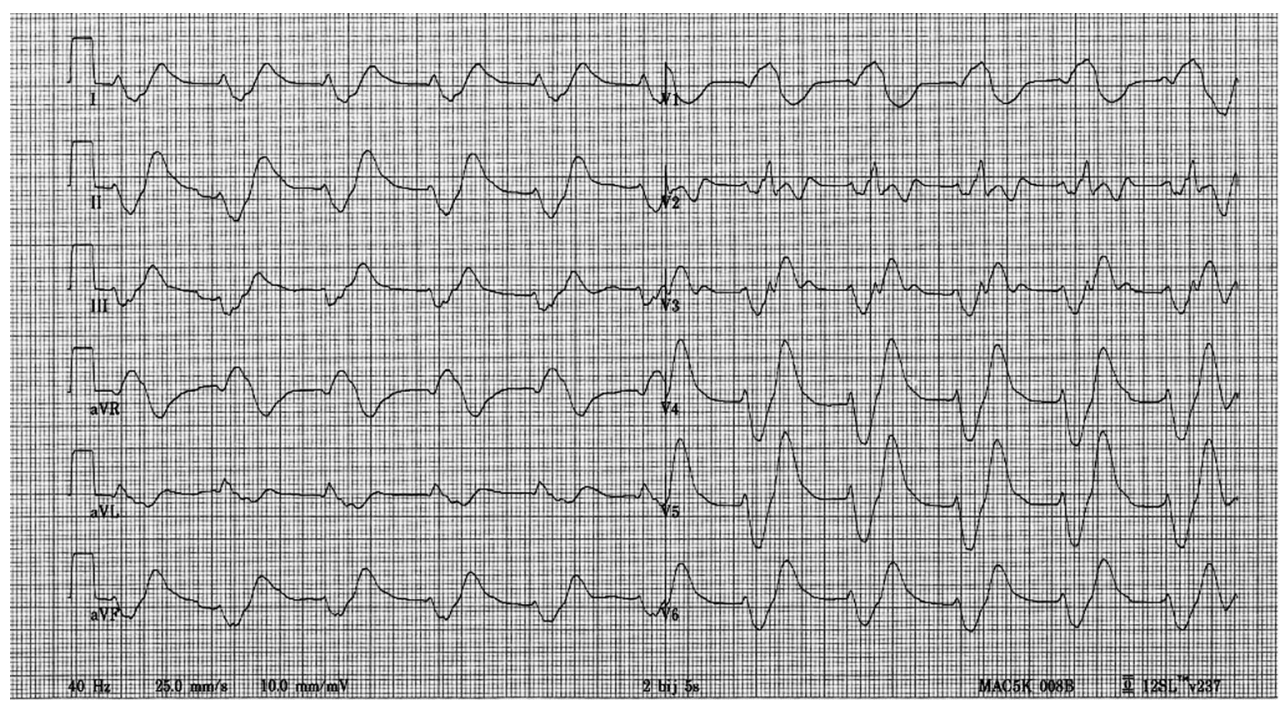

S.L. Gerritse $(\bowtie)$

Amphia Hospital,

Molengracht 21,

4818 CK Breda, The Netherlands

e-mail: sgerritse@amphia.nl

E.H.C.C. Janssen

Erasmus MC,

Rotterdam, The Netherlands 